\title{
Cannabinoids reduce hyperalgesia and inflammation via interaction with peripheral $\mathrm{CB}_{1}$ receptors
}

\author{
Jennelle Durnett Richardson ${ }^{\mathrm{a}, 1}$, Sonja Kilo ${ }^{\mathrm{b}, 2}$, Kenneth M. Hargreaves ${ }^{\mathrm{a}, \mathrm{b}, *}$ \\ ${ }^{a}$ Department of Pharmacology, University of Minnesota, Minneapolis, MN 55455, USA \\ ${ }^{\mathrm{b}}$ Department of Restorative Sciences, University of Minnesota, Minneapolis, MN 55455, USA
}

Received 25 July 1997; received in revised form 10 November 1997; accepted 25 November 1997

\begin{abstract}
Central antinociceptive effects of cannabinoids have been well documented. However, relatively little is known about the peripheral effects of the cannabinoids on inflammation. In the present study, we evaluated the effects of peripherally administered cannabinoids on three indices of inflammation: carrageenan-induced thermal hyperalgesia, carrageenan-induced edema, and capsaicin-induced plasma extravasation. In addition, we determined the effect of cannabinoids on capsaicin-evoked neuropeptide release from isolated rat hindpaw skin. Our results indicate that cannabinoids produce antihyperalgesia via interaction with a peripheral $\mathrm{CB}_{1}$ receptor. Peripheral, but not systemic, administration of $0.01 \mathrm{ng}$ anandamide inhibited the induction of hyperalgesia. Peripheral administration of anandamide also attenuated hyperalgesia after its development via interaction with the $\mathrm{CB}_{1}$ cannabinoid receptor subtype as indicated by its reversal with the $\mathrm{CB}_{1}$ receptor antagonist SR 141716A. Additionally, peripheral, but not systemic, administration of $0.01 \mathrm{ng}$ anandamide inhibited edema. Peripherally administered cannabinoids also interacted with $\mathrm{CB}_{1}$ receptors to inhibit capsaicin-evoked plasma extravasation into the hindpaw. One potential mechanism for the anti-inflammatory actions of the cannabinoids is the inhibition of neurosecretion from the peripheral terminals of nociceptive primary afferent fibers. This hypothesis is supported by the finding that anandamide inhibited capsaicinevoked release of calcitonin gene-related peptide from isolated hindpaw skin. Collectively, these results indicate that cannabinoids reduce inflammation via interaction with a peripheral $\mathrm{CB}_{1}$ receptor. A potential mechanism for this effect is the inhibition of neurosecretion from capsaicin-sensitive primary afferent fibers. (C) 1998 International Association for the Study of Pain. Published by Elsevier Science B.V.
\end{abstract}

Keywords: Cannabinoid; Peripheral; Hyperalgesia; Capsaicin; Neurotransmitter release; Carrageenan

\section{Introduction}

Reports of marijuana-induced analgesia date back millennia (Hall et al., 1994). However, studying the antinociceptive and antihyperalgesic roles of cannabinoids has proved difficult because of the lack of identified receptors and selective agonists and antagonists. Recently, the $\mathrm{CB}_{1}$ and $\mathrm{CB}_{2}$ receptor subtypes were cloned and determined to be members of the $G$ protein-coupled receptor family (Matsuda

\footnotetext{
* Corresponding author. Department of Endodontics, Dental School, University of Texas Health Science Center, 7703 Floyd Curl Drive, San Antonio, TX 78284, USA. Tel.: +1 210 5673381; fax: +1 210 5673389; e-mail: hargreaves@uthscsa.edu

${ }^{1}$ Current address: Department of Neurobiology, Harvard Medical School, Boston, MA 02115, USA.

${ }^{2}$ Current address: Institut für Physiologie und exp. Pathophysiologie, Universitätsstr. 17, D-91054 Erlangen, Germany.
}

et al., 1990; Munro et al., 1993). Additionally, in the last few decades selective synthetic cannabinoids have been developed and endogenous cannabinoids discovered (Lemberger and Rowe, 1975; Johnson et al., 1981; D'Ambra et al., 1992; Devane et al., 1992; Hanus et al., 1993; Mechoulam et al., 1995; Sugiura et al., 1995). Such developments have resulted in the determination that activation of central cannabinoid receptors produces antinociception (Yaksh, 1981; Herkenham et al., 1991; Lichtman and Martin, 1991; Martin et al., 1993, 1995, 1996; Smith et al., 1994; Hohmann et al., 1995; Lichtman et al., 1996; Hohmann and Herkenham, 1997; Richardson et al., 1998a,b).

While the role of peripheral cannabinoid receptors in nociceptive modulation is not as well understood as that of the central cannabinoid receptors, peripheral $\mathrm{CB}_{2}$ receptors have been reported to modulate inflammation. Palmitoylethanolamide, a selective $\mathrm{CB}_{2}$ cannabinoid receptor 
agonist, can attenuate mechanical hyperalgesia induced by carrageenan (Mazzari et al., 1996). One potential mechanism for the antihyperalgesic effect of palmitoylethanolamide is the inhibition of mast cell degranulation (Facci et al., 1995; Mazzari et al., 1996) which would modulate the release of histamine and serotonin. Both of these compounds are capable of producing vasodilatation, increased vascular permeability (plasma extravasation), and activation of nociceptors. These contribute to the observed effects of hyperthermia, edema, and hyperalgesia which are characteristic of carrageenan-induced hyperalgesia (Vinegar et al., 1976; Hargreaves et al., 1988; Rang et al., 1994). While the role of peripheral $\mathrm{CB}_{2}$ receptors in inflammation has been evaluated, the potential role of peripheral $\mathrm{CB}_{1}$ receptors is not known.

The $\mathrm{CB}_{1}$ receptor has been found throughout the central nervous system. Although binding studies have found peripheral tissues to be negative for cannabinoid binding sites (Jansen et al., 1992; Lynn and Herkenham, 1994; RinaldiCarmona et al., 1996), $\mathrm{CB}_{1}$ cannabinoid receptor mRNA is detectable in a number of peripheral tissues (Galiègue et al., 1995; Shire et al., 1995). We have previously demonstrated that activation of spinal $\mathrm{CB}_{1}$ receptors can result in both antihyperalgesia and inhibition of neuropeptide release from central terminals of capsaicin-sensitive primary afferent nociceptive fibers (Richardson et al., 1998b). Additionally, we have demonstrated that cannabinoid binding sites can be measured in sensory neurons (Richardson et al., 1998b). Hohmann and Herkenham (1997) have reported that $\mathrm{CB}_{1}$ receptor mRNA is expressed in substance $\mathrm{P}$ containing neurons in the dorsal root ganglia. Thus, we have hypothesized that $\mathrm{CB}_{1}$ cannabinoid receptors are synthesized in sensory neurons and transported bidirectionally to both the peripheral and central terminals of primary afferent nociceptive fibers. Furthermore, activation of these $\mathrm{CB}_{1}$ receptors could serve to inhibit neuropeptide release which, in the periphery, could result in both anti-inflammatory and antihyperalgesic effects. These hypotheses were tested in the present study.

\section{Methods}

\subsection{Animals}

Male Sprague-Dawley rats (Harlan, Indianapolis, IN) were maintained on a 12:12 light:dark cycle with free access to food and water. All procedures were approved by the University of Minnesota Animal Care and Use Committee.

\subsection{Reagents}

Reagents were obtained from the following companies: anandamide and methanandamide, Cayman Chemical (Ann Arbor, MI); SR 141716A (N-(piperidin-1-yl)-5-(4-chlorophenyl)- 1(2,4-dichlorophenyl)-4-methyl-1H-pyrazole-3- carboxyamide), a gift from Sanofi Recherche (Montpellier, France); capsaicin, Fluka (Ronkonkoma, NY); CGRP antisera (MI-2), kindly provided by Mike Iadorola; goat antirabbit antisera coupled to ferric beads, PerSeptive Diagnostics (Boston, MA); thiorphan, Bachem (Torrance, CA); all other reagents, Sigma (St. Louis, MO).

\subsection{Thermal hyperalgesia}

Paw withdrawal latencies were recorded using the radiant heat method (Hargreaves et al., 1988). Briefly, animals were placed in a clear acrylic box on a glass platform (Plantar Test, Ugo Basile, Italy). A beam of radiant heat was applied through the platform to the plantar surface of the hindpaw. A photocell detected paw withdrawal and the latency was recorded. After recording baseline paw withdrawal latencies in duplicate, animals received an intraplantar (i.pl.) injection of $3 \mathrm{mg}$ carrageenan in a $100 \mu \mathrm{l}$ volume. This was immediately followed by either a $50 \mu \mathrm{l}$ i.pl. or intraperitoneal (i.p.) injection of the endogenous cannabinoid anandamide $(0.01 \mathrm{ng})$ with vehicle $(1 \%$ ethanol) injection in the opposite site to maintain a double-dummy experimental design. Paw withdrawal latencies were recorded in duplicate $1 \mathrm{~h}$ after drug administration. In another set of studies, paw withdrawal latencies were recorded $2 \mathrm{~h}$ after carrageenan administration. This was followed by a $50 \mu \mathrm{l}$ i.pl. injection of anandamide (10 $\mathrm{ng}$ ), $100 \mathrm{ng}$ of the selective $\mathrm{CB}_{1}$ receptor antagonist SR 141716A (Rinaldi-Carmona et al., 1994; Felder et al., 1995; Rinaldi-Carmona et al., 1995), anandamide (10 ng)/SR 141716A (100 ng), or vehicle ( $1 \%$ ethanol). The final paw withdrawal latency was recorded in duplicate at $2.5 \mathrm{~h}$ post-carrageenan. Treatments were randomly allocated to animals and observers were blind to treatment allocations.

\subsection{Edema}

Edema was measured using a plethysmometer (Stoelting, Chicago, IL). After baseline paw volumes were measured, animals received a bilateral i.pl. injection of $3 \mathrm{mg}$ carrageenan. This was followed by either a unilateral $50 \mu \mathrm{l}$ i.pl. injection of $0.01 \mathrm{ng}$ anandamide and an i.p. injection of the $1 \%$ ethanol/saline vehicle or a unilateral i.pl. injection of the vehicle and an i.p. injection of $0.01 \mathrm{ng}$ anandamide. Paw volumes were measured again $3 \mathrm{~h}$ after drug administration.

\subsection{Plasma extravasation}

Plasma extravasation was determined as described by Joris et al. (1990) with slight modification. Animals were anesthetized with sodium pentobarbital $(50 \mathrm{mg} / \mathrm{kg})$ and injected intravenously (i.v.) with $75 \mathrm{mg} / \mathrm{kg}$ Evans blue dye. After $5 \mathrm{~min}$ they received a $50 \mu \mathrm{l}$ i.pl. injection of either the vehicle $(0.1 \%$ ethanol/saline $)$, methanandamide $(175$ ng), SR 141716A (250 ng), or methanandamide (175 ng)/ 
SR $141716 \mathrm{~S}(250 \mathrm{ng})$. After another $5 \mathrm{~min}$ they received a $20 \mu \mathrm{g}$ i.pl. injection of capsaicin $(50 \mu \mathrm{l})$. Twenty minutes after capsaicin, $6 \mathrm{~mm}$ punch biopsies were collected from the hind paw plantar skin and extracted with $1 \mathrm{ml}$ formamide for $24 \mathrm{~h}$ and then read on a spectrophotometer at a wavelength of $568 \mathrm{~nm}$ to determine optical density. These values were compared to a standard curve in order to determine the amount of Evans blue dye in each sample.

\subsection{Superfusion}

A model of rat skin superfusion has recently been developed in our laboratory (Kilo et al., 1997). In this model, immunoreactive calcitonin gene-related peptide (iCGRP) release can be evoked from an in vitro preparation of rat hindpaw skin in a concentration-dependent manner by capsaicin. The $\mathrm{EC}_{50}$ for this effect is approximately 30 $\mu \mathrm{M}$ with maximal release occurring at $100 \mu \mathrm{M}$. Capsaicin-evoked release can be inhibited by the elimination of calcium from the buffer, addition of the capsaicin receptor antagonist capsazepine, or neonatal treatment of the animals with capsaicin to destroy capsaicin-sensitive fibers. In the present study, we have used the rat skin superfusion model to evaluate the ability of anandamide to inhibit neurosecretion from the peripheral terminals of capsaicin-sensitive fibers.

The dorsal hindpaw skin was dissected from proximal digits to the ankle $(209 \pm 8 \mathrm{mg})$. The biopsy was placed in a $2 \mathrm{cc}$ chamber with the corium side exposed to a continual flow of oxygenated synthetic interstitial fluid (SIF) buffer $\left(34^{\circ} \mathrm{C}, \mathrm{pH}=7.4\right.$, ca. $250 \mu \mathrm{l} / \mathrm{min}$; Brandel Superfusion Pump, Brandel, Gaithersburg, MD). SIF buffer consists of $\mathrm{NaCl}(108 \mathrm{mM}), \mathrm{KCl}(3.5 \mathrm{mM}), \mathrm{MgSO}_{4}(0.7 \mathrm{mM})$, $\mathrm{NaHCO}_{3}(26 \mathrm{mM}), \mathrm{NaH}_{2} \mathrm{PO}_{4}(1.67 \mathrm{mM})$, Na gluconate (9.6 mM), $\mathrm{CaCl}_{2}(1.5 \mathrm{mM})$, glucose $(5.5 \mathrm{mM})$, sucrose $(7.6 \mathrm{mM})$, ascorbate $(0.09 \mathrm{mM})$, and thiorphan $(10 \mu \mathrm{M})$. A similar buffer has been used in electrophysiology experiments in rat hindpaw skin (Reeh, 1986). The superfusate was collected into test tubes by a fraction collector (Gilson, Middleton, WI). Each fraction represents $10 \mathrm{~min}$ of collection time. Following equilibration of the tissue and baseline collection (ca. $90 \mathrm{~min}$ ), anandamide or vehicle was administered for $10 \mathrm{~min}$. Capsaicin was then co-administered in the presence of the pretreated drug or vehicle for 7 min. Superfusate was collected for an additional eight fractions.

\subsection{Radioimmunoassay}

Superfusate was analyzed for immunoreactive calcitonin gene-related peptide (iCGRP) using a previously validated radioimmunoassay (RIA). The CGRP antiserum binds near the C-terminal end of CGRP and does not cross-react with cholecystokinin, neuropeptide $\mathrm{Y}$, or other peptides with similar C-terminal residues, such as the FMRF-amide peptides. Immediately following the experiment, samples were pre-incubated for $48 \mathrm{~h}\left(4^{\circ} \mathrm{C}\right)$ with $100 \mu \mathrm{l}$ of the antibody and then received $100 \mu \mathrm{l}$ of $\left[{ }^{125} \mathrm{I}\right] \mathrm{CGRP}_{28-37}$ (approximately $20000-25000 \mathrm{cpm}$ ) and $50 \mu \mathrm{l}$ of goat anti-rabbit antisera coupled to ferric beads. After another $48 \mathrm{~h}$ incubation, the $\left[{ }^{125} \mathrm{I}\right] \mathrm{CGRP}_{28-37}$ bound to the CGRP antibody was separated from free via immunomagnetic separation (PerSeptive Diagnostics, Boston, MA). The liquid was aspirated from each test tube, and the immunoprecipitated reaction product was counted on a gamma counter. Standard curves were generated with all drugs to exclude the possibility of nonspecific effects in the RIA. iCGRP levels were determined for each fraction using logit-log analysis. Under non-equilibrium conditions, the minimum detection limit for the assay is approximately $2-3 \mathrm{fmol} /$ tube with $50 \%$ displacement at $10-30 \mathrm{fmol} /$ tube. The intra- and inter-assay coefficients of variation are less than $5 \%$ and $12 \%$, respectively.

\subsection{Statistics}

Data were analyzed with contrast, $t$-test with Welch's correction, ANOVA or ANCOVA followed by a multiple comparison test as appropriate. Results were considered significant when the probability that they occurred due to chance alone was less than 5\% (i.e., $P<0.05$ ). Data are reported as mean \pm SEM.

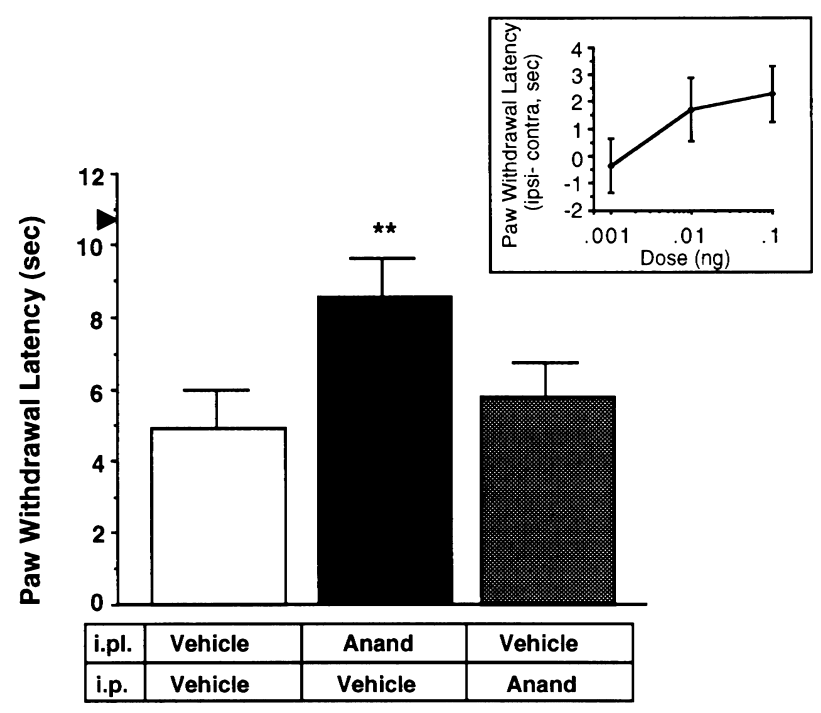

Fig. 1. Effect of systemic and peripheral anandamide administration on carrageenan-induced hyperalgesia. Animals received an intraplantar (i.pl.) injection of carrageenan followed by an intraperitoneal (i.p.) injection of either $0.01 \mathrm{ng}$ anandamide or vehicle. Animals then received an i.pl. injection of the opposite drug. Paw withdrawal latencies were measured prior to carrageenan and $1 \mathrm{~h}$ after carrageenan. Arrowhead depicts mean baseline paw withdrawal values. Data are mean \pm SEM; $n=8$ for all groups. ${ }^{* *} P<0.05$ compared with both vehicle and i.p. anandamide groups. The inset represents results from animals receiving a bilateral i.pl. injection of carrageenan followed by a unilateral i.pl. administration of $0.001,0.01$, or $0.1 \mathrm{ng}$ anandamide. Results are represented as difference between the ipsilateral ('ipsi') paw withdrawal latency and the contralateral ('contra') paw withdrawal latency $1 \mathrm{~h}$ after carrageenan. Data are mean $\pm \mathrm{SEM} ; n=8$ for all groups. 


\section{Results}

We first evaluated whether peripheral administration of the endogenous cannabinoid anandamide was capable of inhibiting the induction of carrageenan-induced hyperalgesia. There were no differences in baseline paw withdrawal latencies for any of the groups (ANOVA $\left(F_{(2,21)}=1.3\right)$; $P=\mathrm{NS})$. Animals were hyperalgesic $1 \mathrm{~h}$ after intraplantar (i.pl.) administration of carrageenan (11.1 \pm 0.37 vs. $4.94 \pm 1.2 \mathrm{~s} ; P<0.001)$. Intraplantar, but not intraperitoneal (i.p.), administration of anandamide inhibited carrageenan-induced hyperalgesia $\left(P<0.05 ; F_{(1,35)}=4.8\right.$; Fig. 1$)$. Additionally, this effect is dose related (Fig. 1 inset; $P<$ $\left.0.05 ; F_{(4,67)}=2.91\right)$. These results suggest that cannabinoids are capable of blocking the induction of carrageenaninduced hyperalgesia via a local site of action in the periphery rather than by diffusing into the blood stream and being distributed to a distant site of action.

Fig. 2 presents the effect of peripheral versus systemic

\section{A. Ipsilateral Hindpaws}

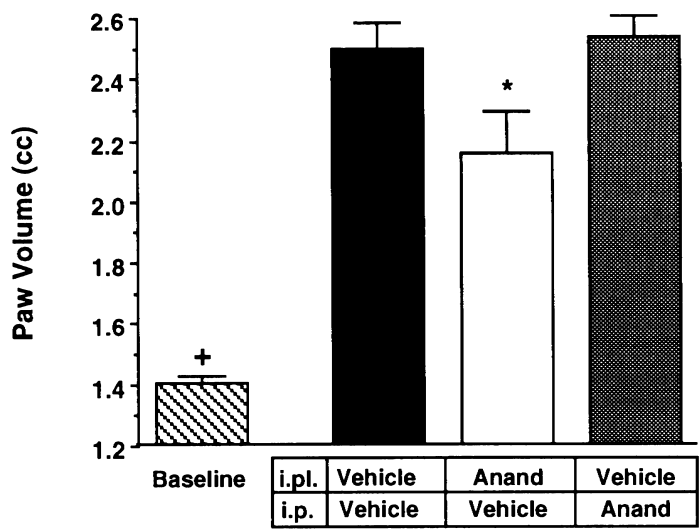

B. Contralateral Hindpaws

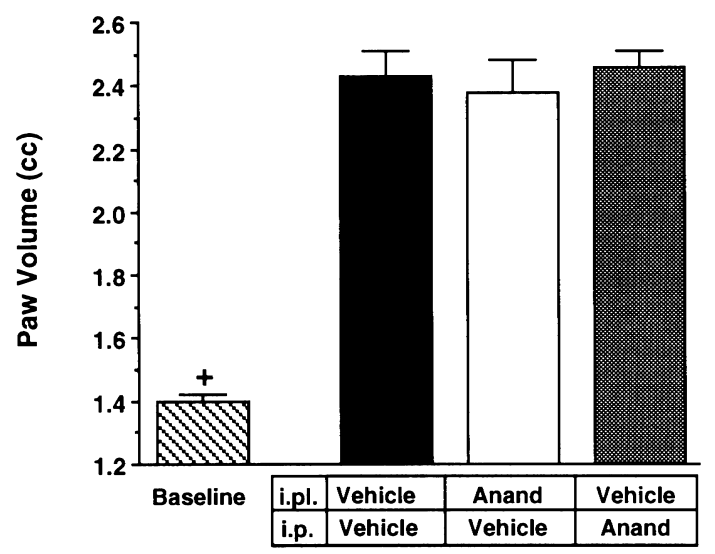

Fig. 2. Effect of systemic versus peripheral anandamide on carrageenaninduced edema. Animals received an i.pl. injection of carrageenan followed by a unilateral i.pl. injection of either $0.01 \mathrm{ng}$ anandamide or vehicle. Animals then received an i.p. injection of the opposite drug. Paw volumes were measured prior to carrageenan ('Baseline') and $3 \mathrm{~h}$ after carrageenan in the ipsilateral (A) and contralateral (B) paw. Data are means $\pm \mathrm{SEM} ; n=8$ for all groups. ${ }^{+} P<0.05$ vs. all other groups; $* P<0.05$ compared with both vehicle and i.p. anandamide. anandamide on the induction of edema by carrageenan. There were no differences in baseline paw volumes between groups for either the right (ANOVA $\left(F_{(2,21)}=0.09\right.$ ); $P=\mathrm{NS})$ or left (ANOVA $\left.\left(F_{(2,21)}=0.07\right) ; P=\mathrm{NS}\right)$ paw. Three hours after carrageenan administration there was an increase in paw volume in both paws $(1.40 \pm 0.02$ vs. $2.49 \pm 0.9 \mathrm{ml} ; P<0.05 ;$ ANOVA $\left(F_{(3,44)}=89.3\right)$ and $1.42 \pm 0.02$ vs. $2.43 \pm 0.08 \mathrm{ml} ; \quad P<0.05$; ANOVA $\left.\left(F_{(3,44)}=138.8\right)\right)$. The increased paw volume was reduced by the concurrent unilateral i.pl. administration of anandamide but not by i.p. anandamide administration $(2.15 \pm 0.14$ vs. $2.53 \pm 0.07 \mathrm{ml})$. Additionally, there was no effect of either the unilateral i.pl. or i.p. administration of anandamide on the contralateral paw $(2.38 \pm 0.10$ and $2.46 \pm 0.05$ $\mathrm{ml}$ ). These results suggest that anandamide is capable of inhibiting carrageenan-induced edema via a local site of action in the periphery rather than by diffusing into the blood stream and being distributed to a distant site of action.

In Fig. 1 we demonstrated that anandamide could inhibit the induction of hyperalgesia; we also evaluated whether anandamide could attenuate hyperalgesia once it had been induced (Fig. 3). There were no differences in baseline latencies between the groups (ANOVA $\left(F_{(3,50)}=1.68\right.$ ); $P=\mathrm{NS})$. Two hours post-carrageenan, paw withdrawal latencies were measured to assess the induction of hyperalgesia. There was no difference among the groups in paw withdrawal latencies at the $2 \mathrm{~h}$ timepoint; however, there was an overall decrease in paw withdrawal latencies when compared to baseline latencies indicating the induction of hyperalgesia $(8.97 \pm 0.22$ vs. $3.24 \pm 0.13$ s; Fig. $3 ; P<$ 0.001 ; ANOVA $\left.\left(F_{(5,156)}=91.1\right)\right)$. Immediately following the measurement of paw withdrawal latencies at the $2 \mathrm{~h}$ timepoint, animals received an i.pl. injection of anandamide (10 $\mathrm{ng}$ ), the selective $\mathrm{CB}_{1}$ receptor antagonist SR 1417116A (100 ng), anandamide (10 ng)/SR 141716A (100 ng), or the vehicle. Thermal hyperalgesia was still present $30 \mathrm{~min}$ after vehicle administration $(4.70 \pm 0.48 \mathrm{~s})$. It was, however, attenuated by the i.pl. administration of anandamide $(6.87 \pm 0.48 \mathrm{~s})$. SR $141716 \mathrm{~A}$ administration blocked development of anandamide-induced antihyperalgesia (5.12 \pm $0.45 \mathrm{~s})$ but had no effect on its own $(5.13 \pm 0.35)$. These results suggest that anandamide is capable of inhibiting the maintenance of carrageenan-induced hyperalgesia via interaction with a peripheral $\mathrm{CB}_{1}$ cannabinoid receptor.

Carrageenan-induced edema has been reported to have a neurogenic component (Nagahisa et al., 1992) so we evaluated the ability of the anandamide congener methanandamide, which is reported to be more potent and more stable than anandamide (Abadji et al., 1994), to inhibit plasma extravasation evoked by capsaicin, which selectively induces a neurogenic inflammation (Holzer, 1991). In the absence of capsaicin, $7.3 \pm 2.1 \mu \mathrm{g}$ Evans blue dye was detected in the biopsy (Fig. 4). Evans blue dye was increased with capsaicin administration to $14.0 \pm 2.3 \mu \mathrm{g}$ $\left(P<0.05 ; \quad F_{(1,25)}=4.0\right)$. Intraplantar administration of $175 \mathrm{ng}$ methanandamide blocked the increase in plasma 


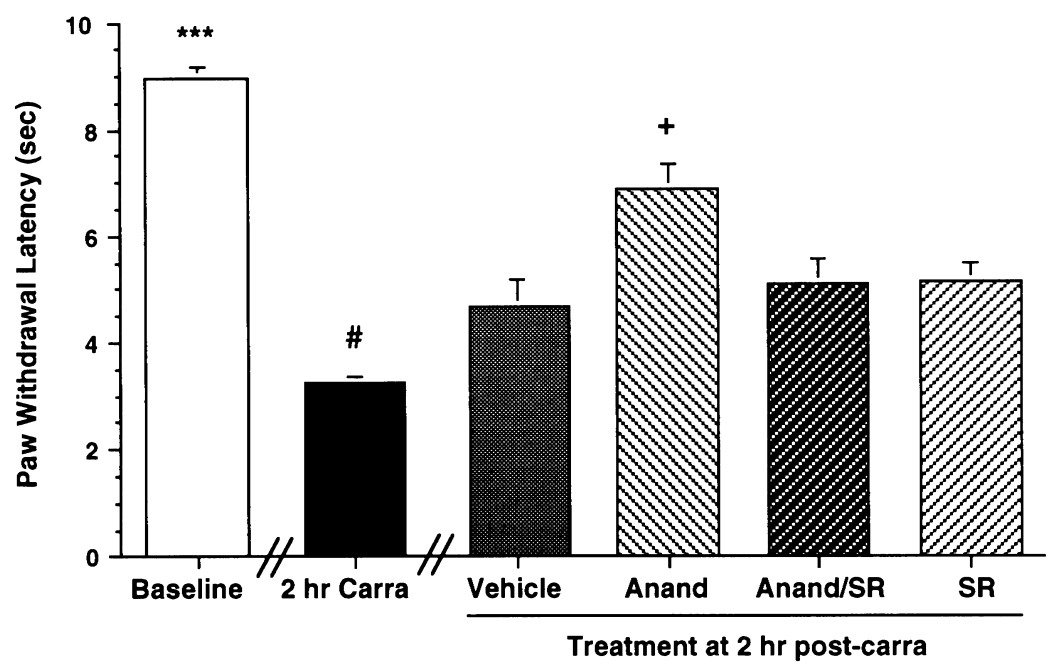

Fig. 3. Effect of peripheral anandamide and SR 141716A administration on paw withdrawal latencies after the induction of hyperalgesia. Animals received an i.pl. injection of carrageenan ( $3 \mathrm{mg}$ ). Paw withdrawal latencies were recorded prior to injection ('Baseline', $n=54)$ and $2 \mathrm{~h}$ after injection ('2 h Carra', $n=54)$. Animals then received an i.pl. injection of either the vehicle ( $1 \%$ ethanol, $n=12), 10 \mathrm{ng}$ anandamide ('Anand', $n=15$ ), $10 \mathrm{ng}$ anandamide/100 ng SR 141716A ('Anand/SR', $n=14$ ), or $100 \mathrm{ng}$ SR 141716A ('SR', $n=13$ ). Paw withdrawal latencies were measured 30 min later. $* * * P<0.001$ vs. all groups; ${ }^{\#} P<0.05$ vs. Vehicle, Anand, Anand/SR, and SR; ${ }^{+} P<0.05$ vs. Vehicle, Anand/SR, and SR.

extravasation $(8.2 \pm 2.5 \mu \mathrm{g})$ in an SR 141716A-sensitive manner $(13.4 \pm 1.3 \mu \mathrm{g})$. These results indicate that peripheral administration of cannabinoids can inhibit neurogenic inflammation as measured by plasma extravasation of Evans blue dye.

One mechanism by which capsaicin induces neurogenic inflammation is via neurosecretion from peripheral terminals of primary afferent nociceptive fibers. The results from the previous experiment, i.e., the ability of cannabinoids to inhibit capsaicin-induced neurogenic inflammation, may be due to the inhibition of capsaicin-evoked neurosecretion. This hypothesis was tested in the next set of experiments and the results are presented in Fig. 5. Anandamide (1 $\mathrm{nM})$ has no effect on basal release but has a simple main effect on inhibiting capsaicin-evoked iCGRP release $(P<$ 0.05; ANOVA $\left(F_{(1,14)}=4.54\right)$; Fig. 5A). Fig. 5B represents the effects of three different concentrations of anandamide on the ability of capsaicin to evoke iCGRP release from isolated rat hindpaw skin. There is a significant increase in iCGRP release with capsaicin or $0.1 \mathrm{nM}$ anandamide/ capsaicin compared to baseline. Both $1 \mathrm{nM}$ anandamide/ capsaicin and $1000 \mathrm{nM}$ anandamide/capsaicin significantly inhibit capsaicin-evoked iCGRP release $(P<0.001$; ANOVA $\left.\left(F_{(4,47)}=17.1\right)\right)$. These results are consistent with the hypothesis that cannabinoids modulate neurogenic inflammation via inhibition of neurosecretion from the peripheral terminals of capsaicin-sensitive fibers.

\section{Discussion}

In this study we demonstrate that intraplantar (i.pl.) administration of the endogenous cannabinoid anandamide inhibits carrageenan-induced thermal hyperalgesia. We have demonstrated that both co-administration of ananda- mide with carrageenan and administration of anandamide after the induction of hyperalgesia are effective in decreasing hyperalgesia. These results indicate that anandamide can inhibit the induction as well as the maintenance of hyperalgesia.

The demonstration that anandamide is capable of inhibiting carrageenan-induced hyperalgesia with intraplantar administration is, in itself, insufficient to conclude that cannabinoids act peripherally to produce antihyperalgesia. It is well supported in the literature that cannabinoids can act at a number of sites in the central nervous system to raise nociceptive thresholds (Yaksh, 1981; Herkenham et al., 1991; Lichtman and Martin, 1991; Martin et al., 1993; Richardson et al., 1998a,b; Smith et al., 1994; Hohmann et al., 1995;

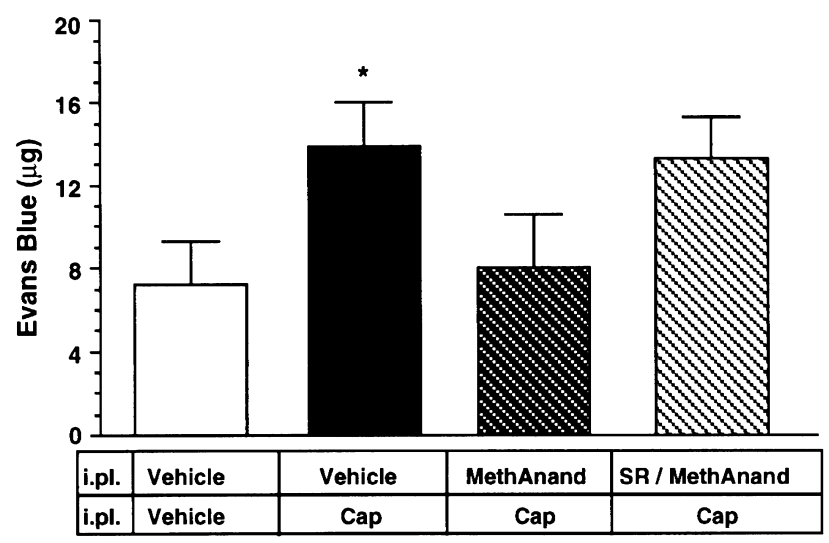

Fig. 4. Effect of the cannabinoid agonist methanandamide on capsaicinevoked neurogenic inflammation. Rats received an i.v. injection of Evans blue dye followed by an i.pl. injection of the vehicle, $175 \mathrm{ng}$ methanandamide ('MethAnand'), or $175 \mathrm{ng}$ methanandamide + $250 \mathrm{ng}$ SR 141716A ('SR/MethAnand'). This was immediately followed by an i.pl. injection of vehicle or capsaicin. Extravasation was determined as described in Section 2. Error bars are SEM; $n=6-19 /$ group. ${ }^{*} P<0.05$ vs. Vehicle/Vehicle and MethAnand/Cap. 
Martin et al., 1995; Lichtman et al., 1996; Martin et al., 1996; Hohmann and Herkenham, 1997; Richardson et al., 1998a,b). Thus, one possible interpretation of the ability of i.pl. administrated anandamide to produce antihyperalgesia is that it is diffusing into the blood stream and acting at distant, potentially central, sites. However, the inability of the peripherally-effective dose of anandamide to produce antihyper-algesia and to inhibit edema when administered systemically (i.e., i.p.) supports a local site of action in the inflamed hindpaw. This is also supported by the lack of contralateral effects following intraplantar anandamide. Additionally, a low dose of the selective $\mathrm{CB}_{1}$ receptor antagonist SR 141716A was capable of inhibiting anandamide-induced antihyperalgesia. Considerably larger systemic doses of SR 141716A are required for centrallymediated cannabinoid effects. For example, i.p. administration of $250 \mathrm{ng}$ SR 141716A is ineffective in antagonizing $\Delta^{9}$-THC-induced antinociception in the tail flick assay (Compton et al., 1996; Reche et al., 1996). In the present study, 100 ng SR 141716A (i.pl.) completely reversed anandamide-induced antihyperalgesia. These results are consistent with a peripheral cannabinoid receptor mediating the observed thermal antihyperalgesia.

Previous studies have suggested that $\mathrm{CB}_{2}$ receptors located on mast cells have an antihyperalgesic role (Mazzari et al., 1996). Our results support both an antihyperalgesic and an anti-inflammatory role for peripheral $\mathrm{CB}_{1}$ receptors. We demonstrated that anandamide has both antihyperalgesic and anti-edemic effects. Most studies have found that anandamide does not activate the $\mathrm{CB}_{2}$ receptor (Facci et al., 1995; Bayewitch et al., 1995) except at very high concentrations (greater than $75 \mu \mathrm{M}$; Lee et al., 1995) supporting the hypothesis that anandamide's effects in the present study are mediated by the $\mathrm{CB}_{1}$ receptor. Moreover, anandamideinduced antihyperalgesia was inhibited by the coadministration of the selective $\mathrm{CB}_{1}$ receptor antagonist SR 141716A. Thus, the reported inability of anandamide to interact with the $\mathrm{CB}_{2}$ receptor, the ability of SR 141716 A to inhibit anandamide's effects, and the lack of activity of anandamide after systemic administration suggest that the effects of ana-
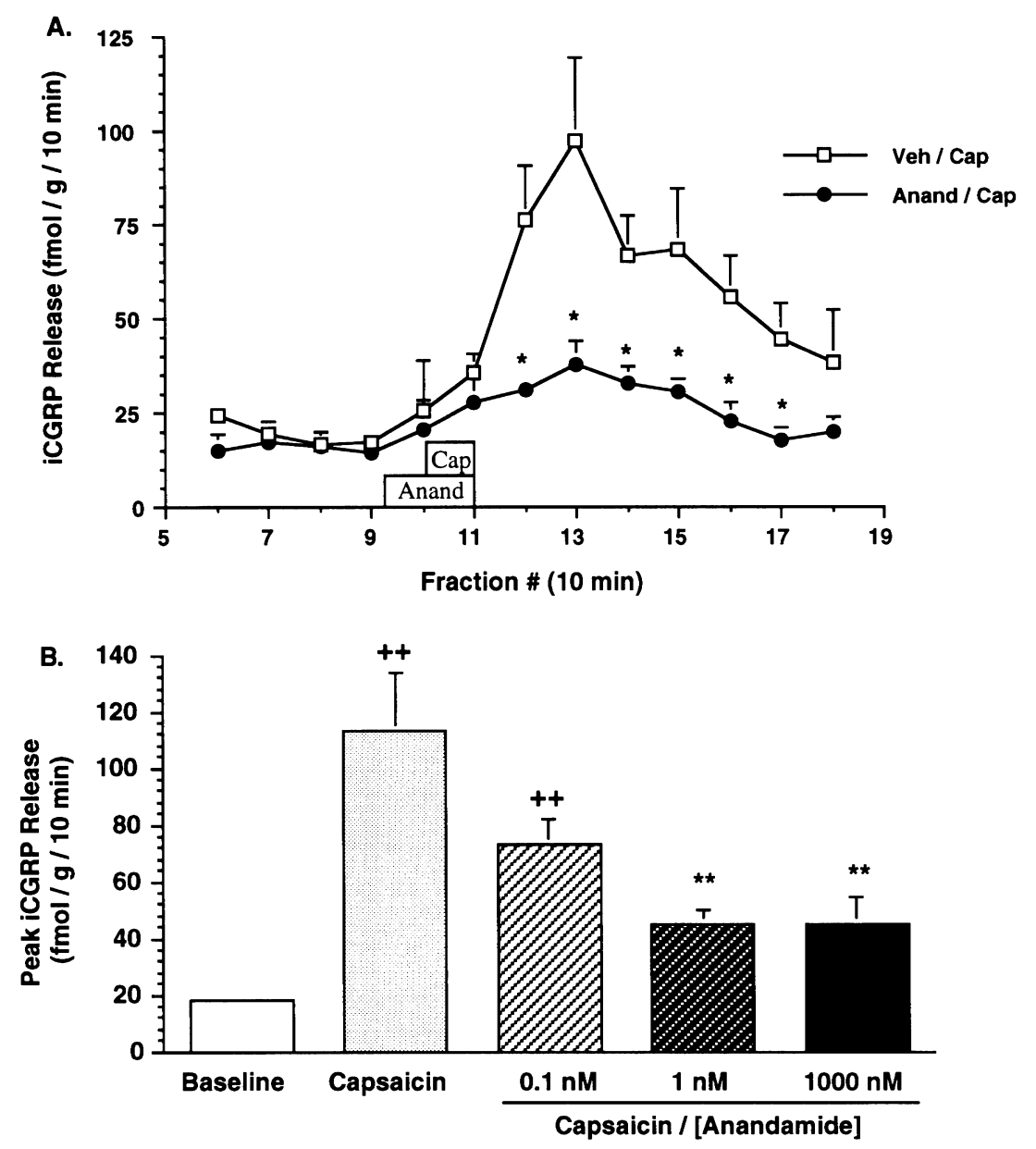

Fig. 5. Effect of anandamide on capsaicin-evoked iCGRP release from rat hindpaw skin. After equilibration, the dorsal hindpaw skin was treated with the vehicle or anandamide ('Anand') for $10 \mathrm{~min}$ followed by capsaicin ('Cap') in the presence of the pretreated drug or vehicle for 7 min. Data are represented as means \pm SEM. Error bars not visible are contained within the symbol. (A) Release of iCGRP under basal conditions and in response to $1 \mathrm{nM}$ anandamide/100 $\mu \mathrm{M}$ capsaicin $(n=6)$ and vehicle/100 $\mu \mathrm{M}$ capsaicin $(n=10)$. $* P<0.05$. (B) Comparison of peak iCGRP release in response to no drug (baseline, $n=26)$, $100 \mu \mathrm{M}$ capsaicin $(n=10), 0.1 \mathrm{nM}$ anandamide/capsaicin $(n=5), 1 \mathrm{nM}$ anandamide/capsaicin $(n=6)$, or $1000 \mathrm{nM}$ anandamide/capsaicin $(n=5) .{ }^{++} P<$ 0.01 vs. baselines; $* * P<0.01$ vs. capsaicin. 
ndamide in this study are mediated via a peripheral $\mathrm{CB}_{1}$ receptor.

Cannabinoids have previously been reported to either reduce carrageenan-induced edema (Sofia et al., 1973) or to have no effect (Kosersky et al., 1973). The anti-edemic effect was attributed to the activation of the pituitary-adrenal axis as demonstrated by the elimination of anti-edema by bilateral adrenalectomy and hypophysectomy. In the present study, we demonstrate that anandamide is effective in inhibiting carrageenan-induced edema via a peripheral site of action as determined both by the lack of effect of i.p. anandamide and by the inability of ipsilateral i.pl. administration of anandamide to inhibit edema in the contralateral hindpaw. The inhibition of edema observed in the present study was not as great as that reported by Sofia et al. (1973). There are at least two potential explanations for the difference. First, we have not conducted a full dose-response curve and thus the dose applied may not be a maximally effective dose. Interpretations from a full dose-response curve with local administration are confounded if the agonist also has systemic effects, such as stimulation of the pituitary-adrenal axis. Thus, it is difficult to determine the efficacy using local drug injection protocols. Secondly, we have not conducted a time-course for the anti-edemic effect of anandamide. Coadministration of anandamide and carrageenan may not produce the greatest effect on edema. Taken together this suggests that cannabinoids are capable of inhibiting edema by both a central and peripheral mechanism.

Edema is a result of plasma extravasation, i.e., the entering of materials from the vascular compartment into the injured tissue due to increased permeability of the microvasculature. Plasma extravasation can be evaluated using Evans blue dye, which binds to circulating albumin and remains mostly in the vascular compartment under control conditions. However, during plasma extravasation, the dyealbumin complex extravasates into the tissue. Capsaicininduced release of neuropeptides is capable of producing plasma extravasation (Nagahisa et al., 1992; Brain, 1996). In the present study, we evaluated the ability of methanandamide, a stable congener of anandamide, to inhibit capsaicin-induced plasma extravasation. Methanandamide inhibited capsaicin-induced plasma extravasation in an SR 141716A-reversible manner. This suggests that cannabinoids inhibit plasma extravasation via interaction with a peripheral $\mathrm{CB}_{1}$ receptor.

There are at least two mechanisms by which activation of the cannabinoid receptor could produce the effects observed in the present study. Activation of the $\mathrm{CB}_{1}$ receptor has been reported to inhibit adenylyl cyclase activity (Howlett, 1984), close certain calcium channels (Caulfield and Brown, 1992; Mackie and Hille, 1992), and enhance certain potassium currents (Deadwyler et al., 1993; Henry and Chavkin, 1995). All three of these could lead to decreased neurotransmitter release. Indeed, in the present study, we demonstrate that anandamide can inhibit capsaicin-induced iCGRP release from isolated hindpaw skin. The inhibition of neurosecretion from primary afferent fibers could result in the reduction of carrageenan-induced hyperalgesia and edema as well as capsaicin-induced plasma extravasation. A second mechanism for the effects of anandamide is the activation of potassium currents and subsequent decreased excitability of the peripheral terminal. Together these mechanisms would result in both the inhibition of neurogenic inflammation and the inhibition of nociceptive transmission to the central nervous system.

The results of this study demonstrate that cannabinoids are capable of inhibiting carrageenan-induced hyperalgesia and edema via interaction with a peripheral $\mathrm{CB}_{1}$ receptor. In addition, cannabinoids inhibit capsaicin-evoked plasma extravasation in vivo and neurosecretion from isolated hindpaw skin. Taken together, these indicate that cannabinoids have a peripheral anti-inflammatory effect mediated by the $\mathrm{CB}_{1}$ receptor.

\section{Acknowledgements}

This work was supported by a predoctoral grant from the Howard Hughes Medical Institute (J.D.R.), the Deutsche Forschungsgemeinschaft (S.K.), and by NIH DE9860 (K.M.H.). The authors wish to thank Sue Buck and Karen Reese for technical assistance.

\section{References}

Abadji, V., Lin, S., Taha, G., Griffin, G., Stevenson, L.A., Pertwee, R.G. and Makriyannis, A., $(R)$-Methanandamide: a chiral novel anandamide possessing higher potency and metabolic stability, J. Med. Chem., 37 (1994) 1889-1893.

Bayewitch, M., Avidor-Reiss, T., Levy, R., Barg, J., Mechoulam, R. and Vogel, Z., The peripheral cannabinoid receptor: adenylate cyclase inhibition of G protein coupling, FEBS Lett., 375 (1995) 143-147.

Brain, S., Sensory neuropeptides in skin. In: P. Geppetti and P. Holzer (Eds.), Neurogenic Inflammation, CRC Press, Boca Raton, FL, 1996, p. 229.

Caulfield, M.P. and Brown, D.A., Cannabinoid receptor agonists inhibit $\mathrm{Ca}^{2+}$ current in NG108-15 neuroblastoma cells via a pertussis toxinsensitive mechanism, Br. J. Pharmacol., 106 (1992) 231-232.

Compton, D.R., Aceto, M.D., Lowe, J. and Martin, B.R., In vivo characterization of a specific cannabinoid receptor antagonist (SR 141716A): inhibition of $\Delta^{9}$-tetrahydrocannabinol-induced responses and apparent agonist activity, J. Pharmacol. Exp. Ther., 277 (1996) 586-594.

D’Ambra, T.E., Estep, K.G., Bell, M.R., Eissenstat, M.A., Josef, K.A., Ward, S.J., Haycock, D.A., Baizman, E.R., Casiano, F.M., Beglin, N.C., Chippari, S.M., Grego, J.D., Kullnig, R.K. and Daley, G.T., Conformationally restrained analogues of pravadoline: nanomolar potent, enantioselective, (aminoalkyl)indole agonists of the cannabinoid receptor, J. Med. Chem., 35 (1992) 124-135.

Deadwyler, S.A., Hampson, R.E., Bennett, B.A., Edwards, T.A., Mu, J., Pacheco, M.A., Ward, S.J. and Childers, S.R., Cannabinoids modulate potassium current in cultured hippocampal neurons, Recept. Channels, 1 (1993) 121-134.

Devane, W.A., Hanus, L., Breuer, A., Pertwee, R.G., Stevenson, L.A., Griffin, G., Gibson, D., Mandelbaum, A., Etinger, A. and Mechoulam, R., Isolation and structure of a brain constituent that binds to the cannabinoid receptor, Science, 258 (1992) 1946-1949. 
Facci, L., Dal Toso, R., Romanello, S., Buriani, A., Skaper, S.D. and Leon, A., Mast cells express a peripheral cannabinoid receptor with differential sensitivity to anandamide and palmitoylethanolamide, Proc. Natl. Acad. Sci. USA, 92 (1995) 3376-3380.

Felder, C.C., Joyce, K.E., Briley, E.M., Mansouri, J., Mackie, K., Blond, O., Lai, Y., Ma, A. and Mitchell, R.A., Comparison of the pharmacology and signal transduction of the human cannabinoid $\mathrm{CB}_{1}$ and $\mathrm{CB}_{2}$ receptors, Mol. Pharm., 48 (1995) 443-450.

Galiègue, S., Mary, S., Marchand, J., Dussossoy, D., Carrière, D., Carayon, P., Bouaboula, M., Shire, D., Le Fur, G. and Casellas, P., Expression of central and peripheral cannabinoid receptors in human immune tissues and leukocyte subpopulations, Eur. J. Biochem., 232 (1995) 54-61.

Hall, W., Solowij, N. and Lemon, J., The therapeutic effects of cannabinoids. In: The Health and Psychological Consequences of Cannabis Use, National Drug Strategy Monograph Series No. 25, Australian Government Publishing Service, 1994, pp. 185-202.

Hanus, L., Gopher, A., Almog, S. and Mechoulam, R., Two new unsaturated fatty acid ethanolamides in brain that bind to the cannabinoid receptor, J. Med. Chem., 36 (1993) 3032-3034.

Hargreaves, K., Dubner, R., Brown, F., Flores, C. and Joris, J., A new and sensitive method for measuring thermal nociception in cutaneous hyperalgesia, Pain, 32 (1988) 77-88.

Henry, D.J. and Chavkin, C., Activation of inwardly rectifying potassium channels (GIRK1) by co-expressed rat brain cannabinoid receptors in Xenopus oocytes, Neurosci. Lett., 186 (1995) 91-94.

Herkenham, M., Lynn, A.B., Little, M.D., Johnson, M.R., Melvin, L.S., de Costa, B.R. and Rice, K.C., Characterization of cannabinoid receptors in rat brain: a quantitative in vitro autoradiographic study, J. Neurosci., 11 (1991) 563-583.

Hohmann, A.G. and Herkenham, M., Localization of cannabinoid receptor (CB1) mRNA in neuronal subpopulations of rat spinal cord and dorsal root ganglia, Abstr. Soc. Neurosci., 23 (1997) 1954.

Hohmann, A.G., Martin, W.J., Tsou, K. and Walker, M., Inhibition of noxious stimulus-evoked activity of spinal cord dorsal horn neurons by the cannabinoid WIN 55,212-2, Life Sci., 56 (1995) 2111-2118.

Holzer, P., Capsaicin: cellular targets, mechanisms of action, and selectivity for thin sensory neurons, Pharmacol. Rev., 43 (1991) 143-201.

Howlett, A.C., Inhibition of neuroblastoma adenylate cyclase by cannabinoid and nantradol compounds, Life Sci., 35 (1984) 1803-1810.

Jansen, E.M., Haycock, D.A., Ward, S.J. and Seybold, V.S., Distribution of cannabinoid receptors in rat brain determined with aminoalkylindoles, Brain Res., 575 (1992) 93-102.

Johnson, M.R., Melvin, L.S., Althuis, T.H., Bindra, J.S., Harbert, C.A., Milne, G.M. and Weissman, A., Selective and potent analgetics derived from cannabinoids, J. Clin. Pharmacol., 21 (1981) 2715-2825.

Joris, J., Costello, A., Dubner, R. and Hargreaves, K.M., Opiates suppress carrageenan-induced edema and hyperthermia at doses that inhibit hyperalgesia, Pain, 43 (1990) 95-103.

Kilo, S., Harding-Rose, C., Hargreaves, K.M. and Flores, C.M., Peripheral CGRP as a marker for neurogenic inflammation: development of a model system for the study of neuropeptide secretion in rat paw skin, Pain, 73 (1997) 201-207.

Kosersky, D.S., Dewey, W.L. and Harris, L.S., Antipyretic, analgesic and anti-inflammatory effects of $\Delta^{9}$-tetrahydrocannabinol in the rat, Eur. J. Pharmacol., 24 (1973) 1-7.

Lee, M., Yang, K.H. and Kaminski, N.E., Effects of putative cannabinoid receptor ligands, anandamide, and 2-arachidonyl-glycerol, on immune function in B6C3F1 mouse splenocytes, J. Pharmacol. Exp. Ther., 275 (1995) 529-536.

Lemberger, L. and Rowe, H., Clinical pharmacology of nabilone, a cannabinoid derivative, Clin. Pharmacol. Ther., 18 (1975) 720-726.

Lichtman, A.H. and Martin, B.R., Spinal and supraspinal components of cannabinoid-induced antinociception, J. Pharmacol. Exp. Ther., 258 (1991) 517-523.

Lichtman, A.H., Cook, S.A. and Martin, B.R., Investigation of brain sites mediating cannabinoid-induced antinociception in rats: evidence sup- porting periaqueductal gray involvement, J. Pharmacol. Exp. Ther., 276 (1996) 585-593.

Lynn, A.B. and Herkenham, M., Localization of cannabinoid receptors and non-saturable high density cannabinoid binding sites in peripheral tissues of the rat: implications for receptor-mediated immune modulation by cannabinoids, J. Pharmacol. Exp. Ther., 268 (1994) 16121622.

Mackie, K. and Hille, B., Cannabinoids inhibit N-type calcium channels in neuroblastoma-glioma cells, Proc. Natl. Acad. Sci. USA, 89 (1992) $3825-3829$.

Martin, W.J., Lai, N.K., Patrick, S.L., Tsou, K. and Walker, J.M., Antinociceptive actions of cannabinoids following intraventricular administration in rats, Brain Res., 629 (1993) 300-304.

Martin, W.J., Patrick, S.L., Coffin, P.O., Tsou, K. and Walker, J.M., An examination of the central sites of action of cannabinoid-induced antinociception in the rat, Life Sci., 56 (1995) 2103-2109.

Martin, W.J., Hohmann, A.G. and Walker, J.M., Suppression of noxious stimulus-evoked activity in the ventral posterolateral nucleus of the thalamus by a cannabinoid agonist: correlation between electrophysiological and antinociceptive effects, J. Neurosci., 16 (1996) 6601-6611.

Matsuda, L.A., Lolait, S.J., Brownstein, M.J., Young, A.C. and Bonner, T.I., Structure of a cannabinoid receptor and functional expression of the cloned cDNA, Nature, 346 (1990) 561-564.

Mazzari, S., Canella, R., Petrelli, L., Marcolongo, G. and Leon, A., N-(2hydroxyethyl) hexadecanamide is orally active in reducing edema formation and inflammatory hyperalgesia by down-modulating mast cell activation, Eur. J. Pharmacol., 300 (1996) 227-236.

Mechoulam, R., Ben-Shabat, S., Hanus, L., Ligumsky, M., Kaminski, N., Schatz, A., Gopher, A., Almog, S., Martin, B., Compton, D., Pertwee, R., Griffin, G., Bayewitch, M., Barg, J. and Vogel, Z., Identification of an endogenous 2-monoglyceride, present in canine gut, that binds to cannabinoid receptors, Biochem. Pharmacol., 50 (1995) 83-90.

Munro, S., Thomas, K.L. and Abu-Shaar, M., Molecular characterization of a peripheral receptor for cannabinoids, Nature, 365 (1993) 61-65.

Nagahisa, A., Kanai, Y., Suga, O., Taniguchi, K., Tsuchiya, M., Lowe, J. and Hess, H.-J., Antiinflammatory and analgesic activity of a non-peptide substance P receptor antagonist, Eur. J. Pharmacol., 217 (1992) 191-195.

Rang, H.P., Bevan, S. and Dray, A., Inflammatory pain. In: P.D. Wall and R. Melzack (Eds.), Textbook of Pain, 3rd Edn., Churchill Livingstone, New York, 1994, pp. 57-78.

Reeh, P.W., Sensory receptors in mammalian skin in an in vitro preparation, Neurosci. Lett., 66 (1986) 141-146.

Reche, I., Fuentes, J.A. and Ruiz-Gayo, M., A role for central cannabinoid and opioid systems in peripheral $\Delta^{9}$-tetrahydrocannabinol-induced analgesia in mice, Eur. J. Pharmacol., 301 (1996) 75-81.

Richardson, J.D., Aanonsen, L. and Hargreaves, K.M., Antihyperalgesic effects of spinal cannabinoids, Eur. J. Pharmacol., (1998a) in press.

Richardson, J.D., Aanonsen, L. and Hargreaves, K.M., Hypoactivity of the spinal cannabinoid system results in NMDA-dependent hyperalgesia, J. Neurosci. 18 (1998b) 451-457.

Rinaldi-Carmona, M., Barth, F., Héaulme, M., Shire, D., Calandra, B., Congy, C., Martinez, S., Maryani, J., Neliat, G., Caput, D., Ferrara, P., Soubrié, P., Parelière, J.C. and Le Fur, G., SR 141716A, a potent and selective antagonist at the brain cannabinoid receptor, FEBS Lett., 350 (1994) 240-244.

Rinaldi-Carmona, M., Barth, F., Heaulme, M., Alonso, R., Shire, D., Congy, C., Soubrie, P., Brelière, J.-C. and Le Fur, G., Biochemical and pharmacological characterization of SR 141716A, the first potent and selective brain cannabinoid receptor antagonist, Life Sci., 56 (1995) 1941-1947.

Rinaldi-Carmona, M., Pialot, F., Congy, C., Redon, E., Barth, F., Bachy, A., Brelière, J.-C., Soubrié, P. and Le Fur, G., Characterization and distribution of binding sites for $\left[{ }^{3} \mathrm{H}\right] \mathrm{SR}$ 141716A, a selective brain (CB1) cannabinoid receptor antagonist, in rodent brain, Life Sci., 58 (1996) 1239-1247.

Shire, D., Carillon, C., Kaghad, M., Calandra, B., Rinaldi-Carmona, M., 
Le Fur, G., Caput, D. and Ferrara, P., An amino-terminal variant of the central cannabinoid receptor resulting from alternative splicing, J. Biol. Chem., 270 (1995) 3726-3731.

Smith, P.B., Compton, D.R., Welch, S.P., Razdan, R.K., Mechoulam, R. and Martin, B.R., The pharmacological activity of anandamide, a putative endogenous cannabinoid, in mice, J. Pharmacol. Exp. Ther., 270 (1994) 219-227.

Sofia, R.D., Nalepa, S.D., Harakal, J.J. and Vassar, H.B., Anti-edema and analgesic properties of $\Delta^{9}$-tetrahydrocannabinol (THC), J. Pharmacol. Exp. Ther., 186 (1973) 646-655.
Sugiura, T., Kondo, S., Sukagawa, A., Nakane, S., Shinoda, A., Itoh, K., Yamashita, A. and Waku, K., 2-Arachidonylglycerol: a possible endogenous cannabinoid receptor ligand in brain, Biochem. Biophys. Res. Commun., 215 (1995) 89-97.

Vinegar, R., Truax, J.F. and Selph, J.L., Quantitative studies of the pathway to acute carrageenan inflammation, Fed. Proc., 35 (1976) $2447-$ 2456.

Yaksh, T.L., The antinociceptive effects of intrathecally administered levonantradol and desacetyllevonantradol in the rat, J. Clin. Pharmacol., 21 (1981) 3345-3405. 